\title{
Estirpes de Bacillus thuringiensis efetivas contra insetos das ordens Lepidoptera, Coleoptera e Diptera
}

\author{
Lílian Botelho Praça( ${ }^{(1)}$, Andréa Cardoso Batista(1), Érica Soares Martins ${ }^{(1)}$, Claúdia Brod Siqueira ${ }^{(1)}$, \\ Daniel Gerheim de Souza Dias ${ }^{(1)}$, Ana Cristina Menezes Mendes Gomes ${ }^{(1)}$, \\ Rosana Falcão( ${ }^{(1)}$ e Rose Gomes Monnerat ${ }^{(1)}$
}

\begin{abstract}
(1) Embrapa Recursos Genéticos e Biotecnologia, Caixa Postal 02372, CEP 70849-970 Brasília, DF. E-mail: lilian@cenargen.embrapa.br, andcardosobat@ig.com.br, erica@unb.com.br, clabrod@cenargen.embrapa.br, danielgerheim@yahoo.com.br, anagomes@cenargen.embrapa.br, falcao@cenargen.embrapa.br, rose@cenargen.embrapa.br
\end{abstract}

Resumo - O objetivo deste trabalho foi selecionar entre 300 estirpes de Bacillus thuringiensis as efetivas simultaneamente contra larvas de Spodoptera frugiperda J.E. Smith e Anticarsia gemmatalis Hübner (Lepidoptera: Noctuidae), Anthonomus grandis Boheman (Coleoptera: Curculionidae), Aedes aegypti Linnaeus e Culex quinquefasciatus Say (Diptera: Culicidae). Foram selecionadas duas estirpes de B. thuringiensis, denominadas S234 e S997, que apresentaram atividade contra as três ordens de insetos. As estirpes foram caracterizadas por métodos morfológicos, bioquímicos e moleculares. As mesmas apresentaram duas proteínas principais de $130 \mathrm{e}$ $65 \mathrm{kDa}$, produtos de reação em cadeia da polimerase de tamanho esperado para a detecção dos genes $\operatorname{crylAa}$, crylAb, crylAc, crylB e cry 2 e cristais bipiramidais, cubóides e esféricos.

Termos para indexação: larva, controle biológico, proteína, reação em cadeia da polimerase, combate às pragas, biopesticida.

\section{Bacillus thuringiensis strains effective against insects of Lepidoptera, Coleoptera and Diptera orders}

\begin{abstract}
The aim of this work was to select among 300 strains of Bacillus thuringiensis those which are simultaneously effective against larvae of Spodoptera frugiperda J.E. Smith and Anticarsia gemmatalis Hübner (Lepidoptera: Noctuidae), Anthonomus grandis Boheman (Coleoptera: Curculionidae), Aedes aegypti Linnaeus and Culex quinquefasciatus Say (Diptera: Culicidae). Two strains of B. thuringiensis were selected, S234 and S997, which presented activity against those three insect orders. Both strains were characterized by morphological, biochemical and molecular methods. They have presented two main proteins with 130 and $65 \mathrm{kDa}$, polimerase chain reaction products with expected sizes for detection of the genes crylAa, crylAb, crylAc, crylB and cry 2 and bipiramidal, cubical and spherical crystals.
\end{abstract}

Index terms: larvae, biological control, protein, polymerase chain reaction, pest control, biopesticides.

\section{Introdução}

Cerca de $15 \%$ da safra de alimentos do mundo é perdida por causa do ataque de insetos, cujo controle tem sido feito, predominantemente, com uso de inseticidas químicos (Silva-Filho \& Falco, 2000). Inseticidas químicos são altamente tóxicos e de amplo espectro de ação com conseqüências graves ao homem e ao meio ambiente, além de causar o aparecimento de populações de insetos resistentes. Portanto, é necessário reduzir o uso desses produtos mediante o emprego de alternativas mais seguras de controle. Assim, os agentes de controle biológico, principalmente as bactérias, são uma alternativa econômica e ecologicamente viável.
Dentre as bactérias utilizadas no controle biológico, Bacillus thuringiensis é responsável por 90\%-95\% do mercado de bioinseticidas (Valadares-Inglis et al., 1998) e apresenta ampla distribuição, podendo ser encontrada em praticamente todos os ambientes. Além disso, produz diferentes proteínas tóxicas, denominadas cristais, altamente específicas para os insetos das ordens Lepidoptera, Coleoptera e Diptera e não afetam o homem, os animais e as plantas (Souza et al., 1999).

Os cristais de B. thuringiensis, ao serem ingeridos pelas larvas dos insetos suscetíveis, sofrem ação do $\mathrm{pH}$ intestinal e de proteases, que solubilizam o cristal e ativam as toxinas. Estas, por sua vez, se ligam a receptores localizados no tecido epitelial do intestino da larva, 
ocasionando a quebra do equilíbrio osmótico da célula, que se intumesce e rompe, propiciando o extravasamento do conteúdo intestinal para hemocele do inseto. Em consequiência, a larva pára de se alimentar, entra em paralisia geral e morre por inanição ou septicemia. Não há atividade de $B$. thuringiensis nas fases de pupa e de adulto dos insetos (Monnerat \& Bravo, 2000).

O objetivo deste trabalho foi selecionar entre 300 estirpes de B. thuringiensis as efetivas simultaneamente contra larvas de Spodoptera frugiperda J.E. Smith e Anticarsia gemmatalis Hübner (Lepidoptera: Noctuidae), Anthonomus grandis Boheman (Coleoptera: Curculionidae), Aedes aegypti Linnaeus e Culex quinquefasciatus Say (Diptera: Culicidae).

\section{Material e Métodos}

Foram utilizadas 300 estirpes brasileiras de B. thuringiensis pertencentes ao Banco de Germoplasma de Bactérias Entomopatogênicas da Embrapa Recursos Genéticos e Biotecnologia. As bactérias destinadas aos bioensaios foram desenvolvidas em meio NYSM (Yousten, 1984) por 48 horas a $28^{\circ} \mathrm{C}$ em incubador rotativo a $200 \mathrm{rpm}$. Inicialmente foram realizados bioensaios seletivos das estirpes contra larvas de Spodoptera frugiperda, Anticarsia gemmatalis, Anthonomus grandis, Aedes aegypti e Culex quinquefasciatus. As estirpes que causaram mortalidade igual ou superior a 50\% para todos os insetos em questão foram selecionadas e submetidas a novos bioensaios, para determinação da concentração letal necessária para matar $50 \%$ da população testada $\left(\mathrm{CL}_{50}\right)$.

\section{Bioensaios}

\section{Spodoptera frugiperda}

Os bioensaios foram realizados espalhando-se $35 \mu \mathrm{L}$ da cultura bacteriana na dieta do inseto distribuída previamente em placas de cultivo de células com 24 poços. Após a absorção da cultura bacteriana pela dieta do inseto, uma larva de segundo ínstar foi colocada em cada poço. Uma placa foi mantida sem a cultura bacteriana, como testemunha. A primeira leitura de mortalidade foi feita 48 horas após o início do ensaio, ocasião em que as lagartas foram transferidas para copos de plástico de $50 \mathrm{~mL}$, contendo dieta livre do patógeno. No sétimo dia, foi feita a segunda e última leitura (Monnerat et al., 2001; Silva-Werneck \& Monnerat, 2001).

No cálculo da $\mathrm{CL}_{50}$, foram feitas diluições seriadas da cultura bacteriana liofilizada, após desenvolvimento nas condições acima descritas. Foram testadas dez di- luições de cada estirpe. Os dados de mortalidade obtidos após sete dias foram analisados mediante Probits (Finney, 1971) e a $\mathrm{CL}_{50}$ foi determinada. Bacillus thuringiensis subsp. kurstaki HD-1 (Btk) foi utilizado como padrão e controle positivo.

\section{Anticarsia gemmatalis}

Os bioensaios foram realizados espalhando-se $150 \mu \mathrm{L}$ da cultura bacteriana na dieta distribuída previamente em copos de plástico de $50 \mathrm{~mL}$. Após a absorção da cultura bacteriana pela dieta, dez larvas de segundo ínstar de A. gemmatalis foram colocadas em cada copo. Duas repetições foram feitas e um copo foi deixado sem a cultura bacteriana, como testemunha. A primeira leitura foi feita 48 horas após o início do ensaio, ocasião em que as lagartas foram transferidas para novos copos, contendo dieta livre do patógeno. No quinto dia, foi feita a segunda e última leitura (Monnerat et al., 2001; SilvaWerneck \& Monnerat, 2001).

Para a determinação da $\mathrm{CL}_{50}$, o procedimento utilizado foi idêntico ao descrito em relação a $S$. frugiperda, com exceção da última leitura, realizada no quinto dia. Os dados de mortalidade foram analisados mediante Probits (Finney, 1971) e a $\mathrm{CL}_{50}$ determinada. Bacillus thuringiensis subsp. kurstaki HD-1 (Btk) foi utilizado como padrão e controle positivo.

\section{Anthonomus grandis}

$\mathrm{O}$ bioensaio seletivo foi realizado incorporando-se $10 \mathrm{~mL}$ da cultura bacteriana em $35 \mathrm{~mL}$ de dieta artificial, vertida em placas de Petri (90x15 mm). Após solidificação da dieta, foram feitos 15 furos de aproximadamente $0,6 \mathrm{~mm}^{2}$, onde colocaram-se larvas neonatas (uma por furo). Utilizaram-se quatro repetições e uma placa sem a bactéria serviu como testemunha. No sétimo dia realizou-se a única leitura (Monnerat et al., 2000).

Para a determinação da $\mathrm{CL}_{50}$, diluições seriadas decimais das culturas liofilizadas das estirpes selecionadas foram incorporadas em $35 \mathrm{~mL}$ de dieta artificial do inseto. O restante do método foi desenvolvido conforme o bioensaio seletivo. Os dados de mortalidade obtidos no sétimo dia foram analisados mediante Probits (Finney, 1971) e a $\mathrm{CL}_{50}$ foi determinada. Bacillus thuringiensis subsp. tenebrionis (Btt) foi utilizado como padrão e controle positivo.

\section{Culex quinquefasciatus e Aedes aegypti}

O procedimento na realização do bioensaio seletivo consistiu em colocar $1 \mathrm{~mL}$ da cultura bacteriana em dois copos descartáveis de $200 \mathrm{~mL}$, contendo $100 \mathrm{~mL}$ de água destilada com 25 larvas de segundo ínstar das duas espécies de mosquitos. Foram feitas duas repetições e um 
copo sem a cultura bacteriana representou a testemunha. Após 24 e 48 horas, realizou-se a leitura do número de sobreviventes, determinando-se as estirpes tóxicas aos insetos (Monnerat et al., 2001; Silva-Werneck \& Monnerat, 2001).

Para a determinação da $\mathrm{CL}_{50}$, foram feitas seis diluições seriadas decimais das estirpes selecionadas liofilizadas. O restante foi feito conforme bioensaio seletivo dos dípteros. Os dados de mortalidade obtidos foram analisados mediante Probits (Finney, 1971) e a CL50 foi determinada. Bacillus thuringiensis subsp. israelensis IPS-82 (Bti) foi utilizado como padrão e controle positivo.

\section{Eletroforese de proteínas em gel de poliacri- lamida-SDS}

Esse procedimento foi realizado com as estirpes selecionadas nos bioensaios seletivos, tóxicas a todos os insetos testados. As estirpes bacterianas se desenvolveram em meio NYSM (Yousten, 1984) por 72 horas em incubador rotativo a $28^{\circ} \mathrm{C}$ e $200 \mathrm{rpm}$; as proteínas foram extraídas conforme Lecadet et al. (1991). As preparações de esporos-cristais das estirpes foram analisadas por eletroforese em gel de poliacrilamida-SDS a 10\%, segundo Laemmli (1970), realizada em aparelho de sistema vertical Hoefer miniVE - Amersham Pharmacia, à voltagem constante de $150 \mathrm{~V}$, por 1 hora e 30 minutos.

\section{Caracterização molecular}

O DNA total dos isolados foi extraído segundo Bravo et al. (1998). Foram usados oligonucleotídeos gerais na identificação dos genes cry1, cry2, cry3, cry4, cry5, cry 8 , cry 11 , cry 12 , cry 14 , cry 21 e cyt e, específicos na identificação de $c r y 1$, cry 3, cry 7, cry 8, cry 9 e $c r y 13$ (Ceron et al., 1994, 1995; Bravo et al., 1998). Quinze $\mu \mathrm{L}$ do sobrenadante da cultura foram transferidos para um tubo contendo $12,5 \mu \mathrm{M}$ de cada oligonucleotídeo, 100 mM de dNTP mix, tampão de Taq 1x e 2,5 U de Taq DNA polimerase $(5,0 \mathrm{U})$ em um volume total de $50 \mu \mathrm{L}$. A amplificação foi processada em termociclador. As condições foram as descritas por Ceron et al. (1994, 1995) e Bravo et al. (1998). Após amplificação, $24 \mu \mathrm{L}$ de cada produto de PCR foi analisado em gel de agarose $2 \%$, corado com brometo de etídio e visualizado em luz ultravioleta. As estirpes B. thuringiensis subsp. kurstaki (Btk), B. thuringiensis subsp. tenebrionis (Btt), B. thuringiensis subsp. israelensis (Bti), B. thuringiensis subsp. medellin (Bt med) e B. thuringiensis subsp. jegathesan (Bt jeg) foram utilizadas como padrão.
Purificação de cristais para microscopia eletrônica

Os isolados foram crescidos em meio NYSM (Yousten, 1984) em incubador rotativo a $200 \mathrm{rpm}, \mathrm{a} 30^{\circ} \mathrm{C}$, por 48 a 72 horas até completa esporulação. Na purificação de cristais, foi utilizado o protocolo de Thomas \& Ellar (1983). As amostras foram analisadas em gel de proteínas e armazenadas a $-20^{\circ} \mathrm{C}$.

\section{Microscopia eletrônica de varredura}

As suspensões de cristais das estirpes foram preparadas em liofilizador Labconco, modelo Lyphlock 18. A seguir, as amostras foram depositadas sobre suportes metálicos e cobertas com ouro por $180 \mathrm{~s}$, utilizandose metalizador Emitech, modelo K550 e observadas em microscópio eletrônico de varredura Zeiss, modelo DSM 962.

\section{Resultados e Discussão}

Dentre as 300 estirpes testadas, apenas S234 e S997 causaram mortalidade nas cinco espécies de insetos e foram selecionadas para a continuação do trabalho.

A estirpe $\mathrm{S} 234$ foi a mais efetiva contra $S$. frugiperda e apresentou $\mathrm{CL}_{50}$ três vezes menor que a do padrão Btk utilizado. Já a estirpe $S 997$ se mostrou tão patogênica quanto o padrão, Btk, com valores de $\mathrm{CL}_{50}$ estatisticamente semelhantes. Em relação à A. gemmatalis, as estirpes S234 e S997 se mostraram semelhantes ao padrão Btk (Tabela 1). Os resultados de superioridade ou semelhança de estirpes de B. thuringiensis contra lepidópteros em relação ao padrão Btk já haviam sido relatados por Souza et al. (1999).

Com relação ao coleóptero A. grandis, as estirpes S234 e S997 se mostraram mais efetivas, uma vez que apresentaram $\mathrm{CL}_{50}$ inferior ao padrão Btt. A diferença dos valores absolutos da $\mathrm{CL}_{50}$ da estirpe $\mathrm{S} 997$ chegou a ser 300 vezes inferior da obtida com o padrão Btt (Tabela 2).

Tabela 1. Concentração letal $\left(\mathrm{ng} / \mathrm{cm}^{2}\right)$ das estirpes de Bacillus thuringiensis necessária para matar $50 \%\left(\mathrm{CL}_{50}\right)$ das larvas de segundo ínstar de Spodoptera frugiperda e Anticarsia gemmatalis ${ }^{(1)}$.

\begin{tabular}{|c|c|c|c|c|}
\hline \multirow[t]{2}{*}{ Estirpes } & \multicolumn{2}{|c|}{ S. frugiperda } & \multicolumn{2}{|c|}{ A. gemmatalis } \\
\hline & $\mathrm{CL}_{50}$ & $\mathrm{IC}^{(2)}$ & $\mathrm{CL}_{50}$ & $\mathrm{IC}^{(2)}$ \\
\hline BtK & $285,22 b$ & $201,53-418,73$ & $15,16 \mathrm{a}$ & $5,95-23,06$ \\
\hline $\mathrm{S} 234$ & $90,24 \mathrm{a}$ & $39,32-144,30$ & $17,22 \mathrm{a}$ & $7,74-42,16$ \\
\hline S997 & $525,70 b$ & $387,22-699,79$ & $21,49 \mathrm{a}$ & $13,06-39,39$ \\
\hline
\end{tabular}

${ }^{(1)}$ Médias seguidas pela mesma letra, na coluna, não diferem entre si pela análise de Probits. ${ }^{(2)}$ Intervalo de confiança a $95 \%$ de probabilidade. 
Apesar de as estirpes S234 e S997 terem apresentado toxicidade nos bioensaios seletivos contra $A$. aegypti e C. quinquefasciatus, seus valores de $\mathrm{CL}_{50}$ foram semelhantes entre si e muitas vezes superiores ao padrão Bti, sendo, portanto menos efetivas (Tabela 3). Segundo Dias et al. (2002), não se têm notícias de estirpes de B. thuringiensis mais eficazes que Bti no controle de larvas de mosquitos.

Por meio da análise da eletroforese da mistura de esporos e cristais das estirpes S234 e S997, verificou-se que as preparações são compostas de dois polipeptídios principais de aproximadamente 130 e $65 \mathrm{kDa}$, semelhantes entre si, que correspondem ao perfil do padrão Btk (Höfte et al., 1988; Lereclus et al., 1993) (Tabela 4). $\mathrm{O}$ perfil de $130 \mathrm{kDa}$ é considerado padrão de estirpes ativas contra lepidópteros e coleópteros, e o perfil de $65 \mathrm{kDa}$ é característico de estirpes ativas contra lepidópteros e dípteros, corroborando os resultados obtidos nos bioensaios com as estirpes S234 e S997.

Por meio da PCR, usando DNA total das estirpes S234 e S997 e primers específicos para a detecção de genes da classe cryl, foram obtidos fragmentos de tamanhos esperados. A PCR com os primers CJ1/CJ2 resultou num fragmento de $246 \mathrm{pb}$, indicando a presença do gene crylAa. A PCR com os primers CJ4 e CJ5 resultou num fragmento de $216 \mathrm{pb}$, obtido quando o gene crylAb está presente. A PCR com os primers CJ6 e

Tabela 2. Concentração letal $(\mu \mathrm{g} / \mathrm{mL})$ das estirpes de Bacillus thuringiensis necessária para matar 50\% ( $\left.\mathrm{CL}_{50}\right)$ das larvas neonatas de Anthonomus grandis.

\begin{tabular}{lrc}
\hline Estirpes & $\mathrm{CL}_{50}$ & $\begin{array}{c}\text { Intervalo de confiança a } \\
95 \% \text { de probabilidade }\end{array}$ \\
\hline Btt & $537,0.10^{-3} \mathrm{~b}$ & $81,0-26.287,2.10^{-3}$ \\
S234 & $10,4.10^{-3} \mathrm{a}$ & $4,0-21,9.10^{-3}$ \\
S997 & $1,8.10^{-3} \mathrm{a}$ & $0,4-6,7.10^{-3}$ \\
\hline
\end{tabular}

${ }^{(1)}$ Médias seguidas pela mesma letra, na coluna, não diferem entre si pela análise de Probits.

Tabela 3. Concentração letal $(\mu \mathrm{g} / \mathrm{mL})$ das estirpes de Bacillus thuringiensis necessária para matar $50 \%\left(\mathrm{CL}_{50}\right)$ das larvas de segundo ínstar de Aedes aegypti e Culex quinquefasciatus.

\begin{tabular}{lccccc}
\hline Estirpes & \multicolumn{2}{c}{ A.aegypti } & & \multicolumn{2}{c}{ C. quinquefasciatus } \\
\cline { 2 - 3 } \cline { 5 - 6 } & $\mathrm{CL}_{50}$ & $\mathrm{IC}^{(2)}$ & & $\mathrm{CL}_{50}$ & $\mathrm{IC}^{(2)}$ \\
\hline Bti & $0,0016 \mathrm{a}$ & $0,0012-0,0022$ & & $0,0096 \mathrm{a}$ & $0,0074-0,0130$ \\
S234 & $4,9200 \mathrm{~b}$ & $2,33-17,97$ & & $7,2600 \mathrm{~b}$ & $4,86-15,90$ \\
S997 & $4,4900 \mathrm{~b}$ & $2,06-16,97$ & & $31,0300 \mathrm{~b}$ & $9,45-990,68$ \\
\hline
\end{tabular}

(1) Médias seguidas pela mesma letra, na coluna, não diferem entre si pela análise de Probits. ${ }^{(2)}$ Intervalo de confiança a 95\% de probabilidade.
CJ7 resultou num fragmento de $180 \mathrm{pb}$, indicando a presença de crylAc, e com os primers CJ8 e CJ9 um fragmento de $367 \mathrm{pb}$, indicando a presença do gene crylB. As duas estirpes S234 e S997 e o padrão Btk apresentaram os mesmos genes (Tabela 4). Quando o DNA das estirpes S234 e S997 foi amplificado com primer geral para $c r y 2$, foi obtido um produto de $526 \mathrm{pb}$ evidenciando, assim, a presença do gene cry2 (Tabela 4). A PCR do padrão Btk também apresentou o mesmo fragmento. Os outros primers utilizados não produziram fragmentos de tamanho esperado, indicando que as estirpes não possuem genes cry 3, cry 4, cry 5, cry 7, cry 8 , cry9, cry11, cry 12 , cry 13 , cry 14 , cry 21 e cyt. As PCRs realizadas com as estirpes padrão Bti, Bt jeg, Bt med e Btt apresentaram fragmentos de tamanho esperado para os genes cry 4 , cry 11 , cyt 1 e cyt 2 , cry3, cry7 e cry8, respectivamente.

Provavelmente, a mortalidade causada pelas estirpes S234 e S997 nos insetos S. frugiperda, A. gemmatalis e $A$. grandis se deva ao gene crylB, uma vez que Bradley et al. (1995) observaram a atividade dupla da proteína Cry1Ba contra lepidópteros e coleópteros. Rie et al. (1990) afirmaram que espécies de Spodoptera são tolerantes às proteínas Cry1Aa e Cry1Ab. Com relação a A. gemmatalis, a atividade entomopatogênica das estirpes S234 e S997 pode ocorrer em razão da presença dos genes crylA, como também pela presença do gene cry2, que são ativos contra insetos da ordem Lepidoptera (Dankocsik et al., 1990; Wu et al., 1991). No entanto, a baixa atividade das estirpes S234 e S997 contra os dípteros C. quinquefasciatus e A. aegypti se deve, provavelmente, à presença do gene cry2, já que este gene apresenta baixa atividade contra esta ordem de insetos (Dankocsik et al., 1990; Wu et al., 1991).

A toxicidade de algumas estirpes aos insetos-alvo pode ocorrer por causa das interações sinergísticas entre as toxinas encontradas, ou mesmo, pela interação destas com os esporos. Portanto, se torna necessário realizar e analisar bioensaios com proteínas individuais e em conjunto para confirmar a toxina responsável pela mortalidade (Lee et al., 1996; Schnepf et al., 1998).

Tabela 4. Perfis protéicos e genes cry presentes nas estirpes de Bacillus thuringiensis.

\begin{tabular}{|c|c|c|}
\hline Estirpes & $\begin{array}{l}\text { Perfil protéico } \\
\text { (kDa) }\end{array}$ & Genes \\
\hline S234 & 130 e 65 & cry $1 A a$, cry $1 A b$, cry $1 A c$, cry 2 e $c r y 1 B$ \\
\hline S997 & 130 e 65 & cry $1 A a$, cry $1 A b$, cry $1 A c$, cry 2 e $c r y 1 B$ \\
\hline Btk & 130 e 65 & cry $1 A a$, cry $1 A b$, cry $1 A c$, cry 2 e $\operatorname{cry} 1 B$ \\
\hline
\end{tabular}


A análise morfológica, por meio de microscopia eletrônica de varredura, das estirpes S997 e S234 mostrou que ambas as estirpes possuem cristais bipiramidais, cubóides e esféricos (Figuras 1 e 2). Essas formas vistas mediante exames microscópicos podem fornecer indicações sobre a atividade inseticida dos cristais de uma estirpe (Taylor et al., 1992; Lereclus et al., 1993;

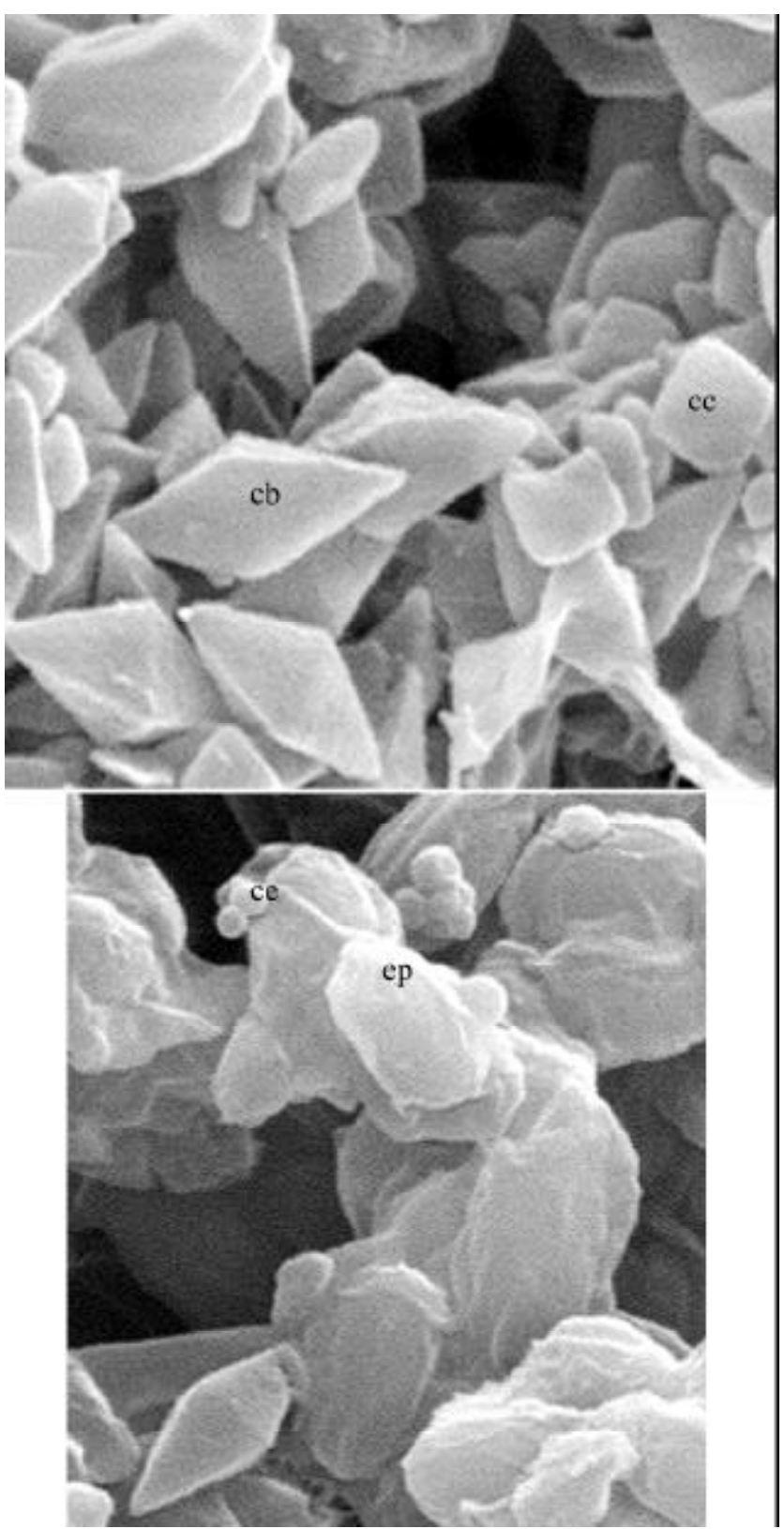

Figura 1. Micrografia eletrônica de varredura da mistura esporos-cristais da estirpe de Bacillus thuringiensis S997. cb: cristal bipiramidal; cc: cristal cubóide; ce: cristal esférico; ep: esporo (aumento de $10.000 \mathrm{x}$ ).

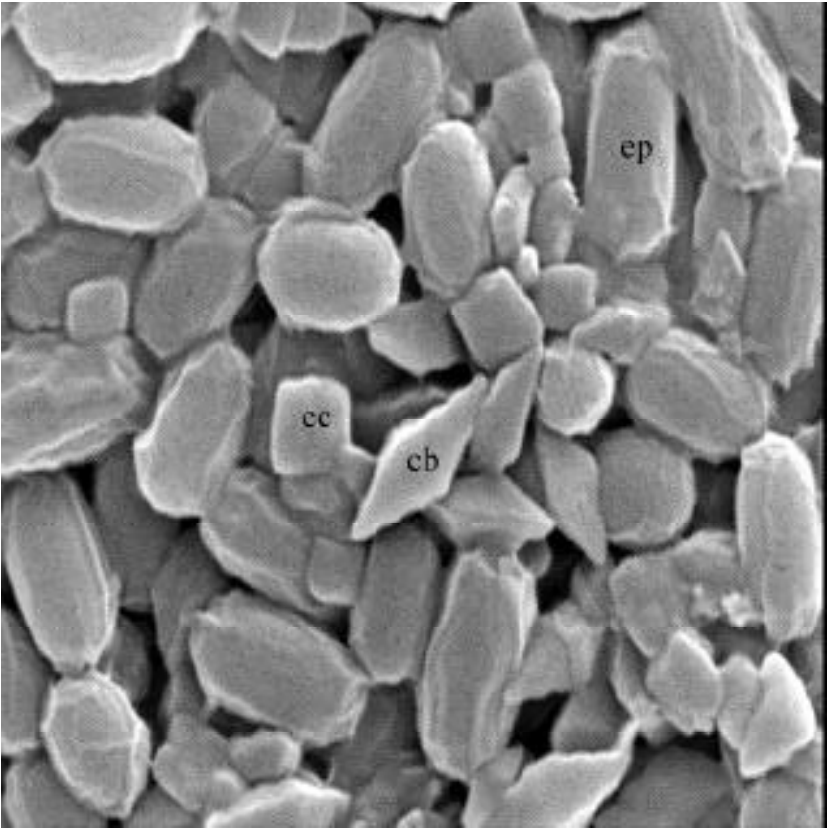

Figura 2. Micrografia eletrônica de varredura da mistura esporos-cristais da estirpe de Bacillus thuringiensis S234. cb: cristal bipiramidal; ep: esporo; cc: cristal cubóide (aumento de $20.000 \mathrm{x}$ ).

Habib \& Andrade, 1998). Cristais bipiramidais podem estar associados às proteínas do tipo Cry1, que apresentam atividade contra Lepidoptera e Coleoptera, e os cristais cubóides podem estar associados com as proteínas do tipo Cry2, que apresentam atividade contra Lepidoptera e Diptera. A estirpe de B. thuringiensis subsp. kurstaki HD-1, utilizada como padrão, apresentou os mesmos cristais que as estirpes S234 e S997, confirmando o observado por Höfte et al. (1988).

\section{Conclusão}

Entre as 300 estirpes de Bacillus thuringiensis, duas, S234 e S997, são efetivas simultaneamente contra larvas de Spodoptera frugiperda, Anticarsia gemmatalis, Anthonomus grandis, Aedes aegypti e Culex quinquefasciatus.

\section{Referências}

BRADLEY, D.; HARKEY, M.A.; KIM, M.K.; BREVER, D.; BAUER, L.S. The insecticidal CryIB protein of Bacillus thuringiensis subsp. thuringiensis has dual specificity to coleopteran and lepidopteran larvae. Journal of Invertebrate Pathology, v.65, p.162-173, 1995. 
BRAVO, A.; SARABIA, S.; LOPEZ, L.; ONTIVEROS, H.; ABARCA, C.; ORTIZ, A.; ORTIZ, M.; LINA, L.; VILLA-LOBOS, F.J.; GUADALUPE, P.; NUNEZ-VALDEZ, M.E.; SOBERÓN, M.; QUINTERO, R. Characterization of cry genes in Mexican Bacillus thuringiensis strain collection. Applied and Environmental Microbiology, v.64, p.4965-4972, 1998.

CERON, J.; COVARRUBIAS, L.; QUINTERO, R.; ORTIZ, A.; ORTIZ, M.; ARANDA, E.; LINA, L.; BRAVO, A. PCR analysis of the cryI insecticidal crystal family genes from Bacillus thuringiensis. Applied and Environmental Microbiology, v.60, p.353-356, 1994.

CERON, J.; ORTIZ, A.; QUINTERO, R.; GUERECA, L.; BRAVO, A. Specific PCR primers directed to identify cryI and cryIII genes within a Bacillus thuringiensis strain collection. Applied and Environmental Microbiology, v.61, p.3826-3831, 1995.

DANKOCSIK, C.; DONOVAN, W.P.; IANY, C.S. Activation of a cryptic crystal protein gene of Bacillus thuringiensis subspecies kurstaki by gene fusion and determination of the crystal protein insecticidal specificity. Molecular Microbiology, v.4, p.2087-2094, 1990.

DIAS, G.S.D.; SILVA, S.F. da; MARTINS, E.S.; SOARES, C.M.S.; FALCÃO, R.; GOMES, A.C.M.M.; PRAÇA, L.B.; DIAS, J.M.C. de S.D.; MONNERAT, R.G. Prospecção de estirpes de Bacillus thuringiensis efetivas contra mosquitos. Brasília: EmbrapaCenargen, 2002. 23p. (Boletim de Pesquisa e Desenvolvimento, 30).

FINNEY, D.J. Probit analysis. Cambridge, England: Cambridge University Press, 1971. 31p.

HABIB, M.E.M.; ANDRADE, C.F.S. Bactérias entomopatogênicas. In: ALVES, S.B. (Ed.). Controle microbiano de insetos. Piracicaba: Fealq, 1998. p.383-446.

HÖFTE , H.; RIE, J. van; JANSENS, S.; HOUTVEN, A. van; VANDERBRUGGEN, H.; VAECK, M. Monoclonal antibody analysis and insecticidal spectrum of three types of lepidopteran-specific insecticidal crystal proteins of Bacillus thuringiensis. Applied and Environmental Microbiology, v.54, p.2010-2017, 1988.

LAEMMLI, U.K. Cleavage of structural proteins during the assembly of the head of bacteriophage T4. Nature, v.227, p.680-685, 1970.

LECADET, M.M.; CHAUFAUX, J.; RIBIER, J.E.; LERECLUS, D. Construction of novel Bacillus thuringiensis strains with different insecticidal activities by transduction and transformation. Applied and Environmental Microbiology, v.58, p.840-849, 1991.

LEE, M.K.; CURTISS, A.; ALCANTARA, E.A.; DEAN, D.H. Synergistic effect of the Bacillus thuringiensis toxins CryIAa and CryIAc on the gypsy moth, Lymantria dispar. Applied and Environmental Microbiology, v.62, p.583-586, 1996.

LERECLUS, D.; DELÉCLUSE, A.; LECADET, M.M. Diversity of Bacillus thuringiensis toxins and genes. In: ENWISTLE, P. F.; CORY, J.S.; BAILEY, M.J.; HIGGS, S. (Ed.). Bacillus thuringiensis: an environmental biopesticide: theory and practice. West Sussex: J. Wiley, 1993. p.37-69.
MONNERAT, R.G.; BRAVO, A. Proteínas bioinseticidas produzidas pela bactéria Bacillus thuringiensis: modo de ação e resistência. In: MELO, I.S.; AZEVEDO, J.L. (Ed.). Controle biológico. Jaguariúna: Embrapa-CNPMA, 2000. v.3, p.163-200.

MONNERAT, R.G.; DIAS, S.C.; OLIVEIRA NETO, O.B. de; NOBRE, S.D.; SILVA-WERNECK, J.O.; SÁ, M.F.G. de. Criação massal do bicudo do algodoeiro Anthonomus grandis em laboratório. Brasília: Embrapa-Cenargen, 2000. 4p. (Comunicado Técnico, 46).

MONNERAT, R.G.; SILVA, S.F.; SILVA-WERNECK, J.O. Catálogo do banco de germoplasma de bactérias do gênero $B a$ cillus. Brasília: Embrapa-Cenargen, 2001. 65p. (Documentos, 60).

RIE, J. van; McGAUGHEY, W.H.; JOHNSON, D.E.; BARNETT, B.D.; MELLAERT, H. van. Mechanism of insect resistance to the microbial insecticide Bacillus thuringiensis. Science, v.247, p.72-74, 1990.

SCHNEPF, E.; CRICKMORE, N.; RIE, J. van; LERECLUS, D.; BAUM, J.; FEITELSON, J.; ZEIGLER, D.R.; DEAN, D.H. Bacillus thuringiensis and its pesticidal crystal proteins. Microbiology and Molecular Biology Reviews, v.62, p.775-806, 1998.

SILVA-FILHO, M.C.; FALCO, M.C. Interação planta-inseto: adaptação dos insetos aos inibidores de proteinase produzidos pelas plantas. Biotecnologia, Ciência \& Desenvolvimento, v.2, p.38-42, 2000.

SILVA-WERNECK, J.O.; MONNERAT, R. Metodologias para caracterização de isolados de Bacillus thuringiensis. Brasília: Embrapa-Cenargen, 2001. 5p. (Circular Técnica, 10).

SOUZA, M.T. de; LIMA, M.I.; SILVA-WERNECK, J.O.; DIAS, J.C.S.; RIBEIRO, B.M. Ultrastructural and molecular characterization of the parasporal crystal proteins of Bacillus thuringiensis subsp. kurstaki S93 active against Spodoptera frugiperda. Biocell, v.23, p.43-49, 1999.

TAYLOR, R.; TIPPET, J.; GIBB, G.; PELLS, S.; PIKE, D.; JORDAN, L.; ELY, S. Identification and characterization of a novel Bacillus thuringiensis $\delta$-endotoxin entomocidal to coleopteran and lepidopteran larvae. Molecular Microbiology, v.6, p.1211-1217, 1992.

THOMAS, W.E.; ELLAR, D.J. Bacillus thuringiensis var. israelensis crystal-endotoxin: effects on insect and mammalian cells in vitro and in vivo. Journal of Cell Science, v.60, p.181-197, 1983.

VALADARES-INGLIS, M.C.C.; SHILER, W.; SOUZA, M.T. de. Engenharia genética de microrganismos agentes de controle biológico. In: MELO, I.S.; AZEVEDO, J.L. (Ed.). Controle biológico. Jaguariúna: Embrapa-CNPMA, 1998. v.1, p.201-230.

WU, D.; CAO, X.L.; BAI, Y.Y.; ARONSON, A.I. Sequence of an operon containing a novel delta-endotoxin gene from Bacillus thuringiensis. FEMS Microbiology Letters, v.65, p.31-35, 1991.

YOUSTEN, A.A. Bacillus sphaericus: microbiological factors related to its potential as a mosquito larvicide. Advances in Biotechnology Processes, v.3, p.315-343, 1984. 
